\title{
Influence of Yarn Twist on the Quality of Rotor Spun Viscose Yarn
}

$$
\text { Jianhui Yang }{ }^{1, a} \text {, Huan Zhang }{ }^{1, b} \text {, Changlin Qian }{ }^{2, c}
$$

${ }^{1}$ Suzhou Institute of Trade \& Commerce, Suzhou, Jiangsu, 215009, China

${ }^{2}$ Nanjing University of Aeronautics \& Astronautics, Nanjing, Jiangsu, 211106, China

ajhyang@szjm.edu.cn, bsummer_zhanghuan@126.com, coolinqian1997@sina.com,

Keyword: viscose;twist;evenness;strength;elongation;rotor spinning

Abstract: The effect of yarn twist on the quality of rotor spun viscose yarn was assessed by analyzing the quality of 30-branch viscose yarn with different yarn twist. The results show that yarn twist has little effect on the quality of the viscose yarn, but excessive low twist will increase the breakage rate.

\section{Introduction}

In the traditional cotton spinning industry, yarn twist has tremendous effects on the quality of yarn, especially while the twist decreases, the strength of yarn decreases greatly, which will increase the difficulty of spinning. At the same time, in order to improve the yarn performance, the yarn twist has to increase, at the expense of production, to ensure the normal operation. In recent years, with the rise of the viscose market, more and more spinning mills have turned their production from cotton-based products into viscose-based, using the same cotton production experience as guide for viscose. However, due to the differences in material types, whether there are any differences between cotton and viscose and how such differences could affect the process design are unknown. In this paper, yarn twist as the main process parameter was studied and its influence on yarn quality was accessed.

\section{Experiment}

Materials. Raw materials are made by drawn sliver produced by different viscose fiber .Use the most proven BD448 rotor spinning machine. The quality parameters of raw material are shown in Table 1.

Table 1 . The quality parameters of raw

\begin{tabular}{ll}
\hline Raw material & Quality \\
Viscose 1 & $100 \% \mathrm{CV} ; 1.1 \mathrm{dtex} ; 38 \mathrm{~mm}$ \\
Viscose 2 & $100 \% \mathrm{CV} ; 1.33 \mathrm{dtex} ; 32 \mathrm{~mm}$ \\
\hline
\end{tabular}

Spinning process design. According to the process requirement and test purpose, design flow chart of the experiment in Fig.1 


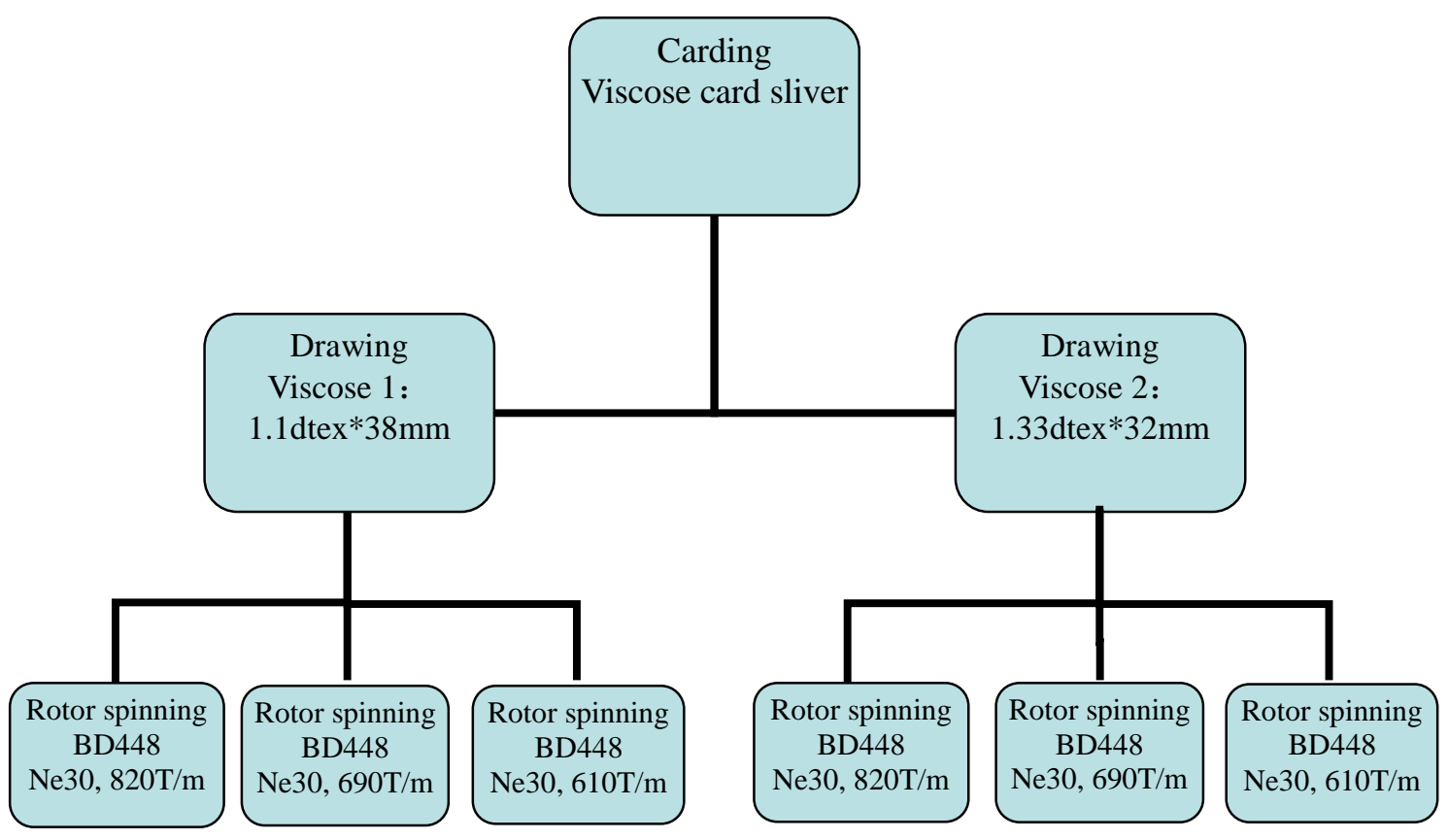

Fig.1 The flow chart of experimental design

Rotor spinning process settings. The most representative $\mathrm{Ne} 30$ viscose is selected in this experiment to ensure the accuracy of the experimental data as far as possible. Two types of materials are chosen, the specific process Settings are shown in Table 2.

Table 2 Rotor spinning process Settings

\begin{tabular}{|c|c|c|}
\hline Yarn count & 30 & 30 \\
\hline Raw material & 1.viscose $1.1 \mathrm{dtex} * 38 \mathrm{~mm}$ & 2.viscose $1.33 \mathrm{dtex} * 32 \mathrm{~mm}$ \\
\hline Rotor spinning machine & Semi-automatic BD 448 & Semi-automatic BD 448 \\
\hline Rotor speed rpm & 100000 & 100000 \\
\hline Rotor type & T34BD & T34BD \\
\hline Carding roller speed rpm & 9000 & 9000 \\
\hline Carding roller type & OK40 NiDi & OK40 NiDi \\
\hline Twist stopper & R4KS5 & R4KS5 \\
\hline False twister & BCK3 & BCK3 \\
\hline Twist /T/m & 820 & 820 \\
\hline
\end{tabular}

Measurement instruments and methods. Yarn breaking strength and breaking elongation were tested by YG020B yarn strength tester, according to the national standard GB/T3916-2013. Yarn evenness and hairiness were tested by USTER4.

\section{Results and Discussion}

The results of rotor spinning viscose yarn quality test are shown in Table 3. 
Table 3 Rotor spinning viscose yarn quality testing

\begin{tabular}{|c|c|c|c|c|c|c|}
\hline The serial number & 1 & 2 & 3 & 4 & 5 & 6 \\
\hline Spindle number & 10 & 10 & 10 & 10 & 10 & 10 \\
\hline Types of materials & 1 & 1 & 1 & 2 & 2 & 2 \\
\hline Yarn count [30] & 30 & 30 & 30 & 30 & 30 & 30 \\
\hline Sliver Tex [tex] & 5000 & 5000 & 5000 & 5000 & 5000 & 5000 \\
\hline 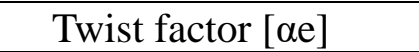 & 3.8 & 3.2 & 2.8 & 3.8 & 3.2 & 2.8 \\
\hline Twist $[\mathrm{T} / \mathrm{m}]$ & 820 & 690 & 610 & 820 & 690 & 610 \\
\hline Rotor type & T34BD & T34BD & T34BD & T34BD & T34BD & T34BD \\
\hline Rotor speed [rpm] & 100000 & 100000 & 100000 & 100000 & 100000 & 100000 \\
\hline Doffing speed $[\mathrm{m} / \mathrm{min}]$ & 122 & 144.9 & 163.9 & 122 & 144.9 & 163.9 \\
\hline Carding roller type & OK40NiDi & OK40NiDi & OK40NiDi & OK40NiDi & OK40NiDi & OK40NiDi \\
\hline $\begin{array}{l}\text { Carding roller speed } \\
{[\mathrm{rpm}]}\end{array}$ & 9000 & 9000 & 9000 & 9000 & 9000 & 9000 \\
\hline Twist stopper & R4KS5 & R4KS5 & R4KS5 & R4KS5 & R4KS5 & R4KS5 \\
\hline Doffing tube plug-in & BCK3 & BCK3 & BCK3 & BCK3 & BCK3 & BCK3 \\
\hline Channel plate & 100 & 100 & 100 & 100 & 100 & 100 \\
\hline $\begin{array}{ll}\text { Process } & \text { negative } \\
\text { pressure }[-\mathrm{Pa}] & \end{array}$ & 4600 & 4600 & 4600 & 4600 & 4600 & 4600 \\
\hline $\begin{array}{ll}\text { Separating } & \text { negative } \\
\text { pressure }[-\mathrm{Pa}] & \end{array}$ & 900 & 900 & 900 & 900 & 900 & 900 \\
\hline ends down & 0 & 0 & 2 & 0 & 0 & 1 \\
\hline $\begin{array}{l}\text { ends down/millenary } \\
\text { spindle hours }[/ \mathrm{kRh}]\end{array}$ & 0 & 0 & 197 & 0 & 0 & 98.5 \\
\hline \multicolumn{7}{|l|}{ Test data } \\
\hline Evenness [CV\%] & 12.44 & 12.6 & 12.64 & 13.44 & 13.4 & 13.44 \\
\hline$-30 \%$ thin $[/ \mathrm{km}]$ & 1223 & 1350 & 1382 & 2011 & 2001 & 1934 \\
\hline$-50 \%$ thin $[/ \mathrm{km}]$ & 1 & 1 & 2 & 7 & 5 & 7 \\
\hline$+35 \%$ thick $[/ \mathrm{km}]$ & 176 & 194 & 199 & 361 & 334 & 369 \\
\hline$+50 \%$ thick $[/ \mathrm{km}]$ & 9 & 10 & 7 & 23 & 22 & 25 \\
\hline$+200 \%$ nep $[/ \mathrm{km}]$ & 23 & 24 & 16 & 31 & 26 & 21 \\
\hline$+280 \%$ nep $[/ \mathrm{km}]$ & 3 & 2 & 1 & 1 & 1 & 0 \\
\hline Hair（Uster） & 3.74 & 3.94 & 3.99 & 4 & 4.21 & 4.32 \\
\hline Breaking strength $[\mathrm{cN}]$ & 259.24 & 267.2 & 272.09 & 237.59 & 255.9 & 259.3 \\
\hline $\begin{array}{l}\text { Breaking } \\
\text { tenacity[cN/tex }]\end{array}$ & 13.16 & 13.57 & 13.81 & 12.06 & 12.99 & 13.16 \\
\hline $\begin{array}{l}\text { Breaking } \\
\text { tenacity[CV\%] }\end{array}$ & 6.95 & 10.05 & 7.68 & 7.98 & 7.79 & 8.02 \\
\hline Extension at break[\%] & 11.86 & 11.8 & 11.91 & 11.01 & 11.45 & 12.05 \\
\hline Extend at break[CV\%] & 6.82 & 8.4 & 7.48 & 9.91 & 8.98 & 8.27 \\
\hline
\end{tabular}

\section{Yarn tensile properties influenced by the twist.}

As you can see from Fig.2,the yarn twist doe not affect the strength and extension of $\mathrm{Ne} 30$ viscose yarn a lot, to the opposite, with the decrease of the twist, the strength A slightly higher. Between the different materials, the strength and extension of the raw material 1 is all better than the raw material 2. 


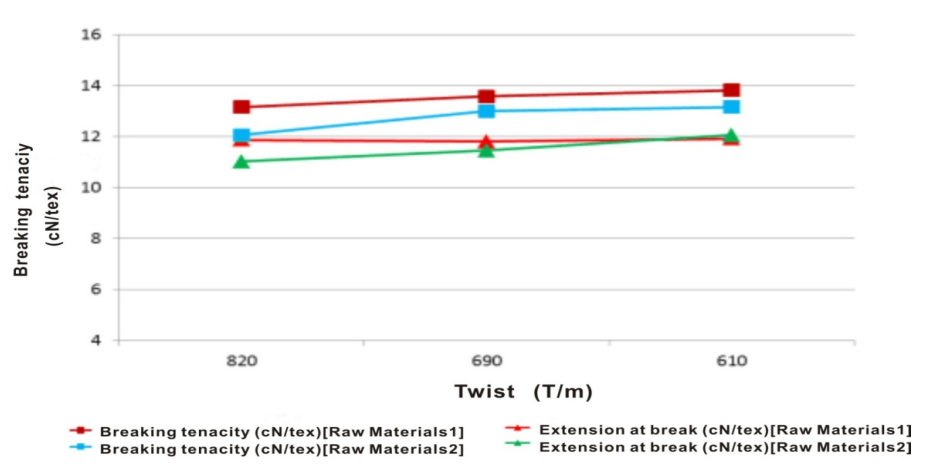

Fig.2 The influence of twist on the Strength and extension of rotor spinning viscose yarn

\section{Yarn count and hair influenced by twist.}

As you can see from the Fig.3, the evenness CV and hair of yarn have no difference with the decrease of twist. But, the evenness $\mathrm{CV}$ of raw material 1 is smaller than the raw material 2, the same to hair.

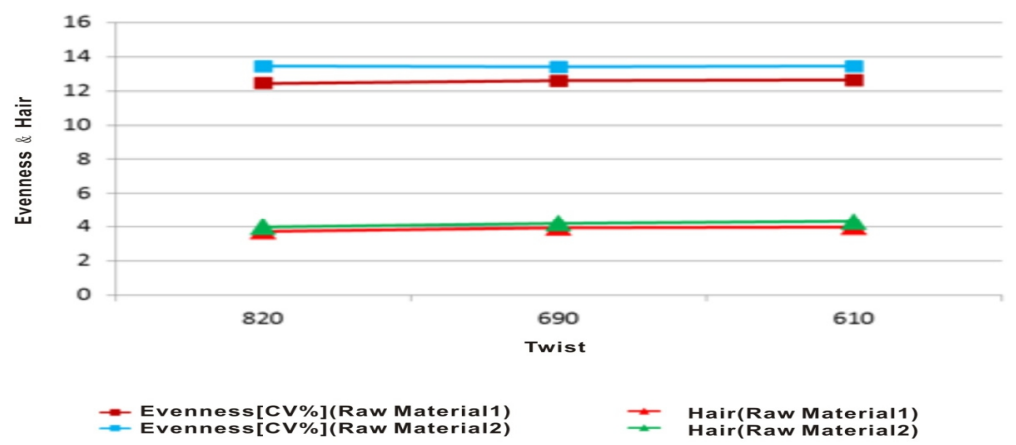

Fig.3 The influence of twist on the evenness $\mathrm{CV}$ and hair of rot or spinning viscose yarn

\section{Yarn thick and thin and nep influenced by twist.}

As shown in Fig.4,obviously, the yarn thin has no difference with the decrease of twist. However, the number of $-30 \%$ thin of raw material 1 is significantly less than the raw material 2.as for $-50 \%$ thin ,the number is too small to Characterize the difference of the raw material.

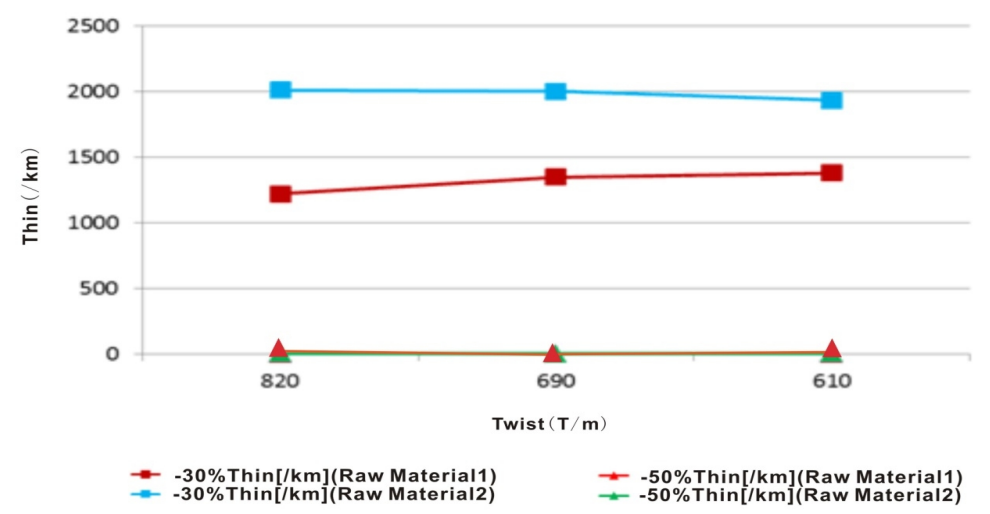

Fig.4 The influence of twist on the thin of rotor spinning viscose yarn

As shown in Fig.5, the thick and thin places of yarn and the nep do not have obvious changes as thechange of twist. However, the thick of raw material 1 is obvious less than raw material 2.Moreever, Due to the less nep number, the nap of raw material 1 and raw material 2 does not 
change significantly in this experiment.

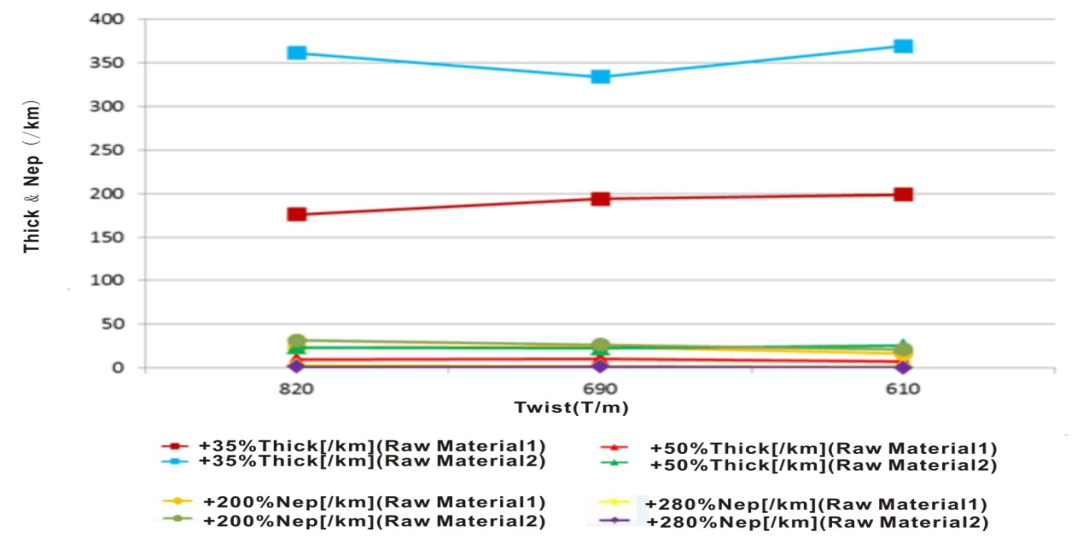

Fig.5 The influence of twist on the thick and nep of rotor spinning viscose yarn

\section{Conclusion}

According to the above test results, we obtain some conclusions as follows:

Between different twist, the yarn strength does not fall when the twist reduces from $820 \mathrm{~T} / \mathrm{m}$ to $610 \mathrm{~T} / \mathrm{m}$. Reducing the twist factor even raise the strength of $100 \%$ viscose yarn in some cases. The spinning stability is not significantly influenced when the twist reduces from $820 \mathrm{~T} / \mathrm{m}$ to $610 \mathrm{~T} / \mathrm{m}$. More fine denier viscose fiber, for example, dtex from $1.33 \mathrm{dtex}$ to $1.33 \mathrm{dtex}$, will significantly improve the quality of yarn such as irregularity of the yarn fineness, yarn strength,the thick and thin places of yarn. Lower twist can get higher yields(Improving the winding speed.

Between different materials, more fine denier viscose fiber has great impact on the yarn strength and elongation. More fine denier viscose fiber can dramatically improve the yarn evenness and hairiness. More fine denier viscose fiber will reduce the nep ,the thick and thin places of yarn.

In conclusion, the spinning mill production for $100 \%$ viscose yarn, should try to reduce the twist on the premise of ensuring the machine efficiency, so that the production has been greatly increased without negative impacts. And, If the customer requires high yarn quality, The mill should try to choose more fine denier viscose fiber for the cases with a little difference in material price, that has obvious improvement of yarn quality, and will get twice the result with half the effort.

\section{Acknowledgements}

This work was financially supported by the Jiangsu Overseas Research \& Training Program for University Prominent Young \& Middle-aged Teachers and Presidents to assist in Research abroad.

\section{References}

[1] $\mathrm{Xu}$ huijun.The rotor spinning products development[J].Cotton spinning technology, 2008,(12):20-21. In Chinese

[2] $\mathrm{Hu}$ Wenjun.The rotor spinning yarn quality analyze system[D].Xinjiang University, 2008.In Chinese

[3] Tang longshi.Rotor spinning system production technology[M].China textile Press, 2005.In Chinese

[4] $\mathrm{Yu}$ congwen, The development of the new spinning technology[J].Cotton spinning technology,2003,(01).In Chinese

[5] Bata.The theory and experimental study of rotor spinning iner twist[D].Shanghai: Donghua university.2004.In Chinese 